\title{
Policies Are Needed to Increase the Reach and Impact of Evidence-Based Parenting Supports: A Call for a Population-Based Approach to Supporting Parents, Children, and Families
}

This is a preprint. The Version of Record of this article is published in Child Psychiatry \& Human Development, and is available online at https://www.springer.com/journal/10578

Frances L. Doyle ${ }^{\mathrm{ab} *}$ f.doyle@,westernsydney.edu.au

Alina Morawska ${ }^{\mathrm{c}}$ alina@psy.uq.edu.au

Daryl J. Higgins d Daryl.Higgins@acu.edu.au

Sophie S. Havighurst ${ }^{\mathrm{e}}$ sophie.h@unimelb.edu.au

Trevor G. Mazzucchelli ${ }^{\mathrm{f}, \mathrm{h}}$ trevor.mazzucchelli@,curtin.edu.au

John W. Toumbourou ${ }^{\mathrm{g}}$ john.toumbourou@,deakin.edu.au

Christel M. Middeldorp ${ }^{i, j}$ c.middeldorp@uq.edu.au

Carys Chainey ${ }^{c}$ c.chainey@uq.edu.au

Vanessa E. Cobham ${ }^{\text {h,j }}$ vanessa@psy.uq.edu.au

Paul Harnett ${ }^{k}$ p.harnett@griffith.edu.au

Matthew R. Sanders ${ }^{\mathrm{c}}$ m.sanders@psy.uq.edu.au

${ }^{a}$ School of Psychology, Faculty of Science, The University of Sydney, Sydney, NSW, Australia

${ }^{\mathrm{b}}$ Western Sydney University, School of Psychology; The MARCS Institute for Brain Behaviour and Development; Transforming early Education And Child Health (TeEACH) Research Centre, Translational Health Research Institute; Sydney, NSW, Australia

${ }^{\mathrm{c}}$ Parenting and Family Support Centre, School of Psychology, The University of Queensland, Brisbane, Queensland, Australia

${ }^{\mathrm{d}}$ Institute of Child Protection Studies, Australian Catholic University

${ }^{\mathrm{e}}$ Mindful: Centre for Training and Research in Developmental Health, The University of Melbourne

${ }^{\mathrm{f}}$ School of Psychology, Curtin University, Perth, Western Australia

${ }^{\mathrm{g}}$ Centre for Social and Early Emotional Development, Deakin University, Geelong, Australia

${ }^{\text {h }}$ School of Psychology, The University of Queensland, Brisbane, Queensland, Australia

${ }^{i}$ Child Health Research Centre, The University of Queensland, Brisbane, Queensland, Australia

${ }^{j}$ Child and Youth Mental Health Service, Children's Health Queensland Hospital and Health Service, Brisbane, Queensland, Australia

${ }^{\mathrm{k}}$ School of Criminology and Criminal Justice, Griffith University

Corresponding author: Dr Frances L. Doyle, f.doyle@westernsydney.edu.au, Western Sydney University, School of Psychology; The MARCS Institute for Brain Behaviour and Development; Transforming early Education And Child Health (TeEACH) Research Centre, Translational Health Research Institute; Sydney, NSW, Australia

Suggested running head: Policies are Needed to Increase EBPSs’ Reach \& Impact 


\begin{abstract}
Parents can be essential change-agents in their children's lives. To support parents in their parenting role, a range of programs have been developed and evaluated. In this paper, we provide an overview of the evidence for the effectiveness of parenting interventions for parents and children across a range of outcomes, including child and adolescent mental and physical health, child and adolescent competencies and academic outcomes, parental skills and competencies, parental wellbeing and mental health, and prevention of child maltreatment and family violence. Although there is extensive research showing the effectiveness of evidencebased parenting programs, these are not yet widely available at a population level and many parents are unable to access support. We outline how to achieve increased reach of evidence-based parenting supports, highlighting the policy imperative to adequately support the use of these supports as a way to address high priority mental health, physical health, and social problems.
\end{abstract}

Keywords: child development; evidence-based parenting supports; parenting; parenting programs; policy 
Parents and caregivers have a central role in optimizing their children's development and wellbeing. Parenting practices are a very important modifiable factor for optimal child development [1]. Child emotional and behavioural problems are prevalent in the population, and are predictive of a range of physical and mental health problems into adulthood [2-4]. Family risk factors show considerable variation across communities and nations. Children are at greater risk for the development of emotional and behavioural problems, as well as child maltreatment, if they grow up in family environments that are conflicted, poorly managed [5] or harsh, punitive, and/or unpredictable [6-8]. Large child population improvements have been demonstrated through parenting changes [5]. To improve parenting practices and optimize child development, a range of parent education and support programs have been developed and evaluated. Parents and caregivers are critical change-agents when intervention is required. Parenting practices can be changed through evidence-based parenting supports (EBPSs) with benefits seen for both parents and children [e.g., 9, 10-12]. For example, in early childhood, EBPSs are the most efficacious interventions for emotional and behavioural problems and this has been demonstrated across diverse cultural and service contexts and populations [13-16]. EBPSs also are effective at changing parenting behaviours $[15,17-22]$ and reducing child maltreatment risk [2325], which addresses key environmental risk factors. Despite positive benefits to children and families [26], the access and reach of EBPSs varies across communities and remains limited in both low- and middle-income countries (LMICs) and highincome countries (HICs) [27]. In order to improve the access and reach of evidencebased prevention and intervention programs to address childhood mental health and behavioural problems and the prevention of child maltreatment, broad implementation and population-level reach of EBPSs is warranted. 
Population-level reach of parenting support involves a blended model of parenting support that combines universal and more targeted approaches with the level of support being proportionate to need (i.e. employing the principle of proportionate universalism [28]). Population-level reach of EBPSs can be achieved by offering multiple levels of support, from light touch to more intensive, that relate to what the parent or caregiver is seeking and has the capacity to engage with [17]. A population-level approach to providing EBPSs also means there is not a one-size-fitsall or one single pathway into receiving an evidence-based parenting program. Principles of minimal sufficiency and proportionate universalism avoid over-serving and recognise that most people are likely to benefit from low-intensity EBPSs that are not costly to deliver at a population level [28]. This approach is also suggested in the World Health Organization's Nurturing Care Framework [29]. A population-level approach from EBPSs using minimal sufficiency (i.e. the least amount of intervention needed to address the presenting problem and prevent future difficulties) and proportionate universalism is considered much more efficient than a stepped care approach as it avoids expensive population screening, ensures that parents and caregivers get what they are looking for, and enables parents and caregivers the option to enter, leave, re-enter, and leave depending on their changing needs as their children develop [30].

Population-level reach also allows for a de-stigmatised offering of EBPSs that all parents and caregivers are able to participate in, that is, not simply offering EBPSs to vulnerable and/or high-risk populations $[30,31]$. In order to adequately support populations at high-risk for child emotional and behavioural problem and child maltreatment, universal offerings of EBPSs have been recommended in order to achieve a shift in the needle at the population level for community-wide problems like 
child maltreatment [31]. Universal offerings of EBPSs do not mean universal uptake of EBPSs (unless such uptake is mandated). Studies that have demonstrated a population-level effect of EBPSs have never reached more than a quarter of eligible parents $[32,33]$. The effects at a population-level of universally available EBPSs occur through a number of mechanisms. In some cases participating parents and caregivers "share the word" and model effective practices with non-participating parents and caregivers in their communities (i.e. social contagion) [33]. In environments, such as schools, population mechanisms may involve EBPSs reducing risk factors such as peer substance use [34] and increasing protective factors such as family management and community monitoring of children [35]. For example, population-level benefits have been observed in population samples despite only a small proportion of the sample being exposed to the EBPSs [33, 34].

Despite all of this evidence, policies do not seem to support the broad implementation and population-level reach of EBPSs in most countries, and certainly not in any LMIC [36]. The majority of the world's children who might benefit from their caregivers participating in EBPSs live in countries where accessing such programs is not a policy priority [36]. It therefore appears that there is a gap between what is known in the literature and what policymakers know. In this paper, we aim to outline the evidence highlighting the importance of parents for optimizing children's healthy development, summarise the evidence that EBPSs improve a broad range of child and parent outcomes, and provide policy recommendations that advocate for better support for parents and improve access to EBPSs. This paper is not a systematic literature review, but a manuscript summarizing relevant literature for the goal of explaining the importance of overcoming barriers to a population-based approach to parenting support. 
We believe that we are uniquely placed to be able to bridge this gap. As Daly [37] highlights in her analytic framework examining parenting support as a policy field, there are a range of political actors expected to promote parenting support with a core set of actors being those in the academic and quasi-academic research community. Indeed, we are part of this community: the Parenting and Family Research Alliance (PAFRA) was formed in 2020 with the vision to advocate for parents and parenting research, and to increase the reach of evidence-based parenting support programs in Australia and internationally. PAFRA is a multidisciplinary research collaboration bringing together leading Australian researchers from a variety of universities and research centres. Although some researchers and policy commentators have written that EBPSs - and policies that support EBPSs - are a type of governance of 'private life' [e.g., 38], PAFRA's position is that parents are critical to optimizing child developmental outcomes, that parents need to be provided with a range of options for being able to develop their parenting knowledge and skills, and that greater access to EBPSs should be a policy priority. Thus, this position underlies this paper and our advocacy to increase the reach EBPSs in Australia and internationally.

\section{The Importance of Parents for Optimising Children's Healthy Development}

Parenting matters for children's optimal development $[1,39,40]$. Recently, the World Health Organization has announced that they are developing guidelines on parenting to prevent child maltreatment and promote positive development in children aged 0-17 years [41]. Parenting and family functioning has been associated with many very high burden-of-disease problems, including mental illness; alcohol and drug abuse; crime and violence; childhood injury; obesity; chronic disease; and educational and economic failure $[42,43]$. Insecure attachment; the lack of a warm and positive 
parent-child relationship; harsh, inflexible, rigid, or inconsistent discipline practices; and inadequate supervision of, and involvement with, children are all associated with child mental health problems [e.g., 44]. Research has also shown that antisocial parental behaviour and depression both have an environmental influence on child psychopathology, even when genetic factors are accounted for [39]. Positive parental interactions are associated with optimal development for children, such as more secure attachment, higher capacity for self-regulation, increased language development, improved communication and cognitive development, and greater prosociality $[45,46]$.

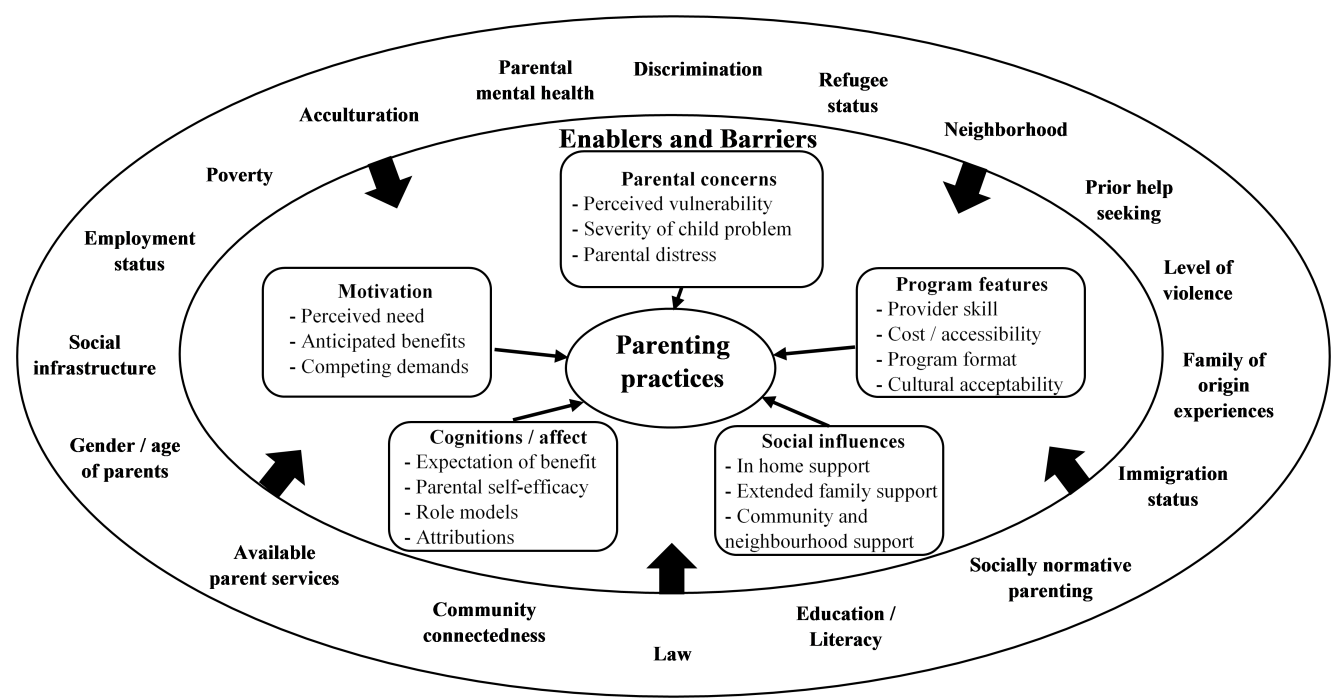

Figure 1. Multiple determinants of parenting practices [47].

Yet parenting is complex and multidetermined; as can be seen in Figure 1.

What is regarded as optimal parenting, for example, changes according to the child's developmental stage and competencies [44], as well as cultural and contextual circumstances [40]. Parenting practices therefore need to evolve throughout the lifespan to stay appropriate and effective [44]. Parents also have differing parenting knowledge and skills, which are further influenced by a variety of contextual issues 
(e.g., child temperament and characteristics, parent self-regulation and parent cognitive functioning), the cultural setting in which they parent, and broader social determinants of health (e.g., chronic and acute stressors that impact family functioning and parenting). The difficulty of the parenting role can be exacerbated in communities that are unsafe (e.g., historical and ongoing trauma) and/or dominated by unhealthy markets (e.g., alcohol, tobacco, illicit drug sales); that lack coordinated parenting services and resources; and, where there is intergenerational transmission of problems (such as unemployment, poverty, crime, and alcohol and other drug addictions). Consequently, parents may become socially isolated, disconnected from the community, overwhelmed, and disempowered, and children are disadvantaged. In order to optimise the wellbeing of children and families, and particularly those living in contexts of disadvantage, caregivers need to be supported to parent as well as possible in order to optimise children's development [40, 48].

Parenting does not just affect children, but parenting competence or selfefficacy also influences parents themselves [47]. The extent to which parents view themselves as competent in their parenting role is associated with parental wellbeing, the use of positive parenting practices and optimal child outcomes [44]. There are a range of collateral effects of EBPSs on parent mental health and health outcomes [21, 49-51]. For example, there has been reductions in maternal depression that have been associated with improved parenting skills [52]. EBPSs offer a way to support parents in their parenting role.

\section{Outlining the Evidence that EBPSs Improve Child and Parent Outcomes}

EBPSs refer to "the full breadth of empirically supported means of helping parents raise their children. These means of support include communication messaging as part of a social marketing campaign, the use of low and higher intensity 
parenting interventions using the Internet, and group and individual face-to-face delivery of parenting interventions" [46].

Evidence-based parenting supports differ from evidence-informed parenting supports as they have been empirically evaluated to be effective in significantly changing outcomes to benefit children and/or parents. Comparatively, evidenceinformed parenting supports may be formulated with evidence in mind but have not been empirically tested. EBPSs provide a higher level of evidentiary support than evidence-informed parenting supports that can be difficult to define and reach agreement on. Although evidence-informed parenting supports may be useful for populations that are hard to reach and where an extensive evidence base has not been established (e.g., families with complex trauma, indigenous communities), the majority of parenting populations should be provided with EBPSs where the empirical evidence is overwhelming.

Decades of research and numerous meta-analyses have established EBPSs to be acceptable to parents in diverse cultural contexts [53], and to produce positive effects in terms of parent behaviour, child behaviour, parental adjustment, and family relationships [e.g., 9, 10-12, 16]. There is also evidence from systematic reviews and meta-analyses that EBPSs work in both HICs and LMICs, with findings suggesting that EBPSs are at least as effective when transported to countries with different cultures and service provisions than those in which the EBPSs were developed [16, 54]. EBPSs also provide a mechanism through which the United Nations Sustainable Development Goals may be attained, as positive parenting practices can promote diverse prosocial outcomes in children and parents $[36,55]$.

As previously outlined, policies do not currently support the broad implementation and population-level reach of EBPSs in HICs or LMICs. In this 
paper, we have presented a range of illustrative examples demonstrating the effectiveness of EBPSs across a range of domains/outcomes relevant to child and family wellbeing in Table 1, so that the evidence for why broad implementation and population-level reach of EBPSs in HICs and LMICs might be warranted. It is also possible, however, that there are several other reasons why policy makers do not currently use EBPSs to address societal problems. As Ramsey and colleagues note effectiveness of the intervention is but one factor in a more complex equation in the research-translation calculus [56]. There may be a problem with the dissemination of EBPSs, for example. There might also be an issue with the framing of using EBPSs by policy makers to create the type of value propositions that they are willing to use their political will to get into policy. It is possible that researchers need to continue to consider how to address these problems when attempting to translate the use of EBPSs and widely disseminate EBPSs. 


\section{Table 1}

Illustrative Exemplars that Capture the Breadth of Diverse Outcomes Influenced by EBPSS

\begin{tabular}{|c|c|}
\hline Domains/outcome areas & Brief commentary \\
\hline $\begin{array}{l}\text { Parental skills, knowledge } \\
\text { and confidence }\end{array}$ & $\begin{array}{l}\text { - There is extensive evidence supported by meta-analyses and systematic reviews for EBPSs resulting in } \\
\text { improvements in parenting skills }[15,17-22,26] \text {, self-efficacy }[15,17,57-59] \text { and knowledge }[18,20,26,60] \\
\text { across a variety of settings and formats for parents of typically developing children in HIC. } \\
\text { - There is also evidence that EBPSs improve parenting skills, across a variety of settings and formats for } \\
\text { parents of typically developing adolescents in LMICs [61] and HICs [62]. } \\
\text { In regards to parents with a child with developmental disabilities, meta-analyses have found that EBPSs } \\
\text { result in improved parent practices, parenting satisfaction and efficacy, parental adjustment, and co-parent } \\
\text { relationships }[14,63] \text {. }\end{array}$ \\
\hline $\begin{array}{l}\text { Child and adolescent } \\
\text { mental health }\end{array}$ & $\begin{array}{l}\text { - There is extensive evidence supported by meta-analyses and systematic reviews for EBPSs resulting in } \\
\text { improvements in behaviour problems for children aged less than } 12 \text {-years-old }[15,17,20,21,26,59,64] \text { and } \\
\text { adolescents [62] across a variety of settings and formats [15, 65]. }\end{array}$ \\
\hline
\end{tabular}




\begin{tabular}{|c|c|}
\hline Domains/outcome areas & Brief commentary \\
\hline & $\begin{array}{l}\text { Evidence shows that EBPSs can reduce internalising problems [65, 66]. } \\
\text { - A review of EBPSs for parents of adolescents in LMICs demonstrated that several EBPSs improved } \\
\text { adolescent psycho-social wellbeing, including reduced internalising and behavioural problems [61]. } \\
\text { - Meta-analyses have found treatment effects of EBPSs for both mixed and specific disability samples, } \\
\text { including children with attention-deficit/hyperactivity disorder [67], autism spectrum disorder [68], language } \\
\text { impairments [69], and parents with intellectual disability [70]. }\end{array}$ \\
\hline Parental wellbeing and & $\begin{array}{l}\text { - There is compelling evidence supported by meta-analyses that EBPSs that focus on reducing child behaviour } \\
\text { problems have demonstrated improvements parental mental health, including reductions in depression, } \\
\text { anxiety and stress [e.g., 21]. } \\
\text { - There is also emerging evidence from reviews that mindfulness-based parenting programs show significant } \\
\text { benefits in reducing parental depressive symptoms [49], and parental stress [51]. } \\
\text { - Further, there is developing evidence from a systematic review and meta-analysis that EBPSs for children } \\
\text { with chronic illness result in improved parental mental health [50]. }\end{array}$ \\
\hline
\end{tabular}




\begin{tabular}{|c|c|}
\hline Domains/outcome areas & Brief commentary \\
\hline & $\begin{array}{l}\text { - An evaluation of a population-level approach for EBPSs focussing on supporting families with children with } \\
\text { developmental disabilities also found that increased access to parenting support resulted in significant } \\
\text { improvements in a range of indices of family functioning [71]. }\end{array}$ \\
\hline $\begin{array}{l}\text { Child and adolescent } \\
\text { academic attainment }\end{array}$ & $\begin{array}{l}\text { - There is emerging experimental and quasi-experimental evidence that both intensive and light-touch EBPSs } \\
\text { during the preschool years can increase academic achievement in primary school [e.g., 72, 73]. } \\
\text { - There is also evidence that EBPSs provided in the early years (before children are aged 3-years) result in } \\
\text { significant improvements in child cognitive development, language development, and motor development; } \\
\text { and these effects were greater in LMICs than HICs [26]. }\end{array}$ \\
\hline $\begin{array}{l}\text { Child and adolescent } \\
\text { competencies }\end{array}$ & $\begin{array}{l}\text { - There is strong evidence that EBPSs have been found to improve emotional and behavioural development for } \\
\text { children aged 3- to 12-years-old [64]. Currently, there is limited high quality evidence to demonstrate these } \\
\text { benefits in children under 3-years-old [64]. } \\
\text { - As outlined in a review of systematic reviews [74], there is good evidence that EBPSs improve social } \\
\text { outcomes for children including parent-child interactions, children's social skills and social competence, }\end{array}$ \\
\hline
\end{tabular}




Domains/outcome areas Brief commentary

emotional stability, and self-control.

- In their review, England-Mason and Gonzalez [75] found that a handful of emotion socialisation parenting programs had demonstrated improvements in children's skills in understanding and regulating emotions.

- In terms of child outcomes for children with a disability, meta-analyses have shown that EBPSs are associated with improvements in child communication skills, social, and other adaptive behaviours [76], as well as reductions in challenging behaviours $[14,63]$.

Child and adolescent

physical health
- There is emerging evidence for the efficacy of EBPSs for parents of children with a chronic health condition.

One systematic review [77] has indicated that EBPSs may lead to improved parent self-efficacy, parenting behaviour, illness severity/control, child quality of life and child behaviour; however, intervention effects were mixed and confined to parent-report outcome measures.

- There are promising outcomes reported across multiple systematic reviews of EBPSs for childhood overweight and obesity. Reductions in weight have been demonstrated in treatment studies [78, 79], in studies delivered during the perinatal period [80], and universally delivered parent support [81], but not for 


\begin{tabular}{|c|c|}
\hline Domains/outcome areas & Brief commentary \\
\hline & $\begin{array}{l}\text { eHealth interventions [82] nor prevention studies [78]. } \\
\text { - There is promising evidence of efficacy supported by systematic reviews for EBPSs that target children's } \\
\text { dietary behaviour [80-83]. } \\
\text { - A systematic review of EBPSs targeting infant sleep also showed small improvements in infant sleep [84]. } \\
\text { - Systematic reviews also demonstrate that EBPSs can prevent adolescent alcohol, tobacco, and illicit drug use } \\
\text { over the short- and long-term [85-88]. }\end{array}$ \\
\hline $\begin{array}{l}\text { Prevention of child } \\
\text { maltreatment and family } \\
\text { violence }\end{array}$ & $\begin{array}{l}\text { - Meta-analyses and reviews have shown a significant effect of EBPSs in preventing or reducing maltreatment } \\
\text { [23-25], including in LMICs [54]. } \\
\text { - Although there is conceptual alignment between the provision of EBPSs and the prevention of child } \\
\text { maltreatment and family violence, relatively few RCTs examine outcome measures relating directly to child } \\
\text { maltreatment and family violence [55]. The majority of the available evidence relates to physical abuse and } \\
\text { neglect often in HICs [55]. Barlow et al. [64] found there was good evidence of modest benefits in improving } \\
\text { outcomes associated with physical abuse and neglect, such as parent and family functioning and child }\end{array}$ \\
\hline
\end{tabular}




\begin{tabular}{|c|c|}
\hline Domains/outcome areas & Brief commentary \\
\hline & $\begin{array}{l}\text { development. } \\
\text { - In a review of the evidence on EBPSs in LMICs at preventing and reducing maltreatment and family } \\
\text { violence, it was shown that EBPSs can be effective in reducing violence (physical and emotional) and neglect } \\
\text { of adolescents, and increasing parental capacity to protect children from sexual violence [89]. } \\
\text { - In a rare study of population-level effects, Prinz et al. [32] used randomisation of the intervention (a tiered, } \\
\text { multi-level approach to parenting support) compared to usual services. They found that provision of EBPSs } \\
\text { led to significant reductions in rates of confirmed child maltreatment cases in the statutory child protection } \\
\text { service, out-of-home care placements, and hospital-treated child maltreatment injuries. } \\
\text { Despite the theoretical alignment, there is a lack of studies examining the role of EBPSs on preventing } \\
\text { domestic violence [90, 91] and the documented impact of interparental conflict, domestic and family } \\
\text { violence on parenting and parent-child relationships [92]. A scoping review of EBPSs in LMICs that aim to } \\
\text { prevent domestic violence and child maltreatment found that there was limited but emerging evidence that } \\
\text { EBPSs can produce positive outcomes for caregivers and children [91]. }\end{array}$ \\
\hline
\end{tabular}




\section{Implications for Policy}

Decades of parenting research have resulted in a wealth of knowledge about the importance of parents as change agents in children's lives and the effectiveness of EBPSs (as shown in Figure 2). Although the list in Table 1 is illustrative, and not exhaustive of all the evidence on EBPSs, it is clear that EBPSs positively affect a range of parent and child outcomes including: parental skills, knowledge and confidence; child and adolescent mental health; parental wellbeing and mental health; child and adolescent academic attainment; child and adolescent competencies; child and adolescent physical health; and prevention of child maltreatment and family violence.

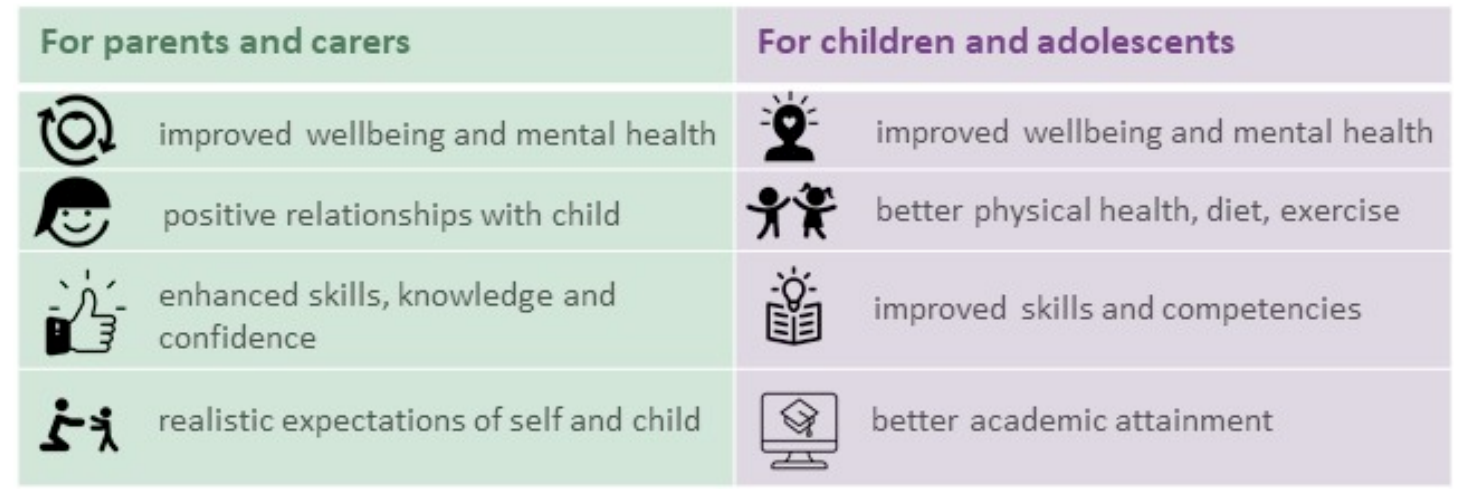

Figure 2. Benefits of evidence-based parenting supports.

Parenting interventions have an extensive evidence base, yet their availability is often limited and relatively few parents access EBPSs [27, 40]. In Australia, for example, only $35 \%$ of parents who had a child needing help for an emotional or behavioural problem reported having their needs fully met [93]. Similarly, in the United States, less than $50 \%$ of youth with severely impairing emotional, behavioural, or developmental disorders had never received intervention [94]. Few policies adequately support the use of EBPSs as a mechanism to support parents and children 
across the world. It is therefore necessary that policies enable access to EBPSs so that children, parents/carers, and families are supported (see Figure 3).

\begin{tabular}{|c|c|c|}
\hline $\begin{array}{l}\text { Accessible: offer services in a } \\
\text { broad range of community } \\
\text { settings: childcare, schools, } \\
\text { healthcare settings }\end{array}$ & $\begin{array}{l}\text { Start low, aim high: offer low } \\
\text { intensity support to all } \\
\text { parents, and increase } \\
\text { intensity where } \\
\text { needed }\end{array}$ & $\begin{array}{l}\text { Promote: share positive } \\
\text { parenting messages, } \\
\text { programs and services } \\
\text { on mainstream and } \\
\text { social media }\end{array}$ \\
\hline $\begin{array}{l}\text { Multi-modal: offer services in } \\
\text { a range of delivery modes - } \\
\text { in-person, telehealth, online }\end{array}$ & $\begin{array}{l}\text { Adapt: tailor for Indigenous } \\
\text { parents, culturally and } \\
\text { linguistically diverse, LGBTIQ+, } \\
\text { fathers, parents of children } \\
\text { with developmental } \\
\text { disabilities, rural and remote }\end{array}$ & $\begin{array}{l}\text { Resources: build capacity and } \\
\text { infrastructure through } \\
\text { workforce tertiary level } \\
\text { training, research and } \\
\text { research funding }\end{array}$ \\
\hline
\end{tabular}

Figure 3. How to enable access for parents and carers.

\section{Theory of Change.}

The "theory of change" from a public health perspective is that children are more likely to follow an optimal development pathway when experts effectively communicate healthy behaviour guidelines to all parents (e.g., child nutrition, activity, online behaviour, violence against others). Parents then need opportunities to improve their skills, capabilities, and confidence using EBPSs that are delivered through trusted (non-stigmatised) universal service delivery platforms. Parenting capability can then be further supported by access to more targeted services based on a progressive approach. This blended model of parenting support combines universal and more targeted approaches with the level of support being proportionate to need (i.e. employing the principle of proportionate universalism [28]) and being minimal sufficient (i.e. providing the least amount of intervention needed to address the presenting problem and prevent future difficulties). As well as providing lowerintensity EBPSs to the broadest group of families, more intense supports are needed 
for those with the highest level of need. These include supports to families delivered at the tertiary level (i.e. statutory child protection services, where harm is imminent or has occurred) where parenting deficiencies (i.e. risk factors for child maltreatment) are clearly apparent. This approach normalises parent education and support at the community level, an important factor for improving engagement in, and use of, EBPSs by parents. Such an approach would involve changes to policy, funding, and practice to ensure that EBPSs are available at the primary prevention level in order to reach the greatest number of parents and families. This population-based approach to implementation of EBPSs can be applicable to both HICs and LMICs. The evidence shows that EBPSs can be effectively transported into a variety of countries; which includes settings in which the EBPSs were not initially designed, in low-resource contexts, as well as settings with high violence rates [16, 17, 54, 89, 95, 96].

The delivery of EBPSs needs to be flexible, with support being offered in traditional in-person services, as well as utilising telehealth and online delivery. Although funding for flexible delivery options was always important to ensure reach to rural and remote families [97, 98], increasing funding for flexible delivery of EBPSs has been of particular importance during and following the COVID-19 pandemic. This is because COVID-19 health priorities (e.g., social distancing measures) have necessitated that in-person services be ceased or reduced, even if only temporarily. Policy makers do not need to be concerned about effectiveness of EBPSs when flexibly delivered, as researchers have already established that technology can be effectively used to deliver parenting support. For example, recent reviews have demonstrated effectiveness for online EBPSs [99, 100]. Moreover, studies have shown that therapist-assisted EBPSs using telephone contact $[101,102]$ and online video conferencing $[97,98,103,104]$ have been effective at improving child 
outcomes (and sometimes parent outcomes too), with high levels of parent satisfaction reported. Researchers have also shown that therapist-assisted EBPSs using online video conferencing are as effective as face-to-face EBPSs [97, 103].

\section{Funding of EBPSs.}

A major barrier to increasing the reach of EBPSs is how these programs are funded in different nations. For example, in Australia, children and adolescents with defined mental health conditions cannot receive a government-funded evidence-based parenting intervention delivered by authorised practitioners because of an anomaly that requires the child to be physically present in a mental health consultation. Removing this barrier to enable parent-only consultations would enable the delivery of several EBPSs. Similarly, as outlined by Weisenmuller and Hilton [105], there are similar challenges in the United States where the provider contracting system results in a service delivery environment that is complicated by insurance coverage (e.g., Medicaid versus private), insurance plans, and whether insurance-provider agreements exist. Comparatively, these funding barriers are not seen in many European nations (e.g., The Netherlands, Germany) where EBPSs are funded by the state. Policy makers need to address funding barriers so that parents are able to access EBPSs.

Some administrations also state they fund programs deemed "evidencebased", but the metrics for this classification vary greatly. Lack of transparency and accountability in the funding of parenting programs is also a major obstacle to accessibility. It can be challenging to establish whether policies are effectively dedicating funding to evidence-based or evidence-informed parenting supports. In some areas of mental health support, it makes sense that evidence-informed practices and practitioners are funded so that timely solutions to important problems can be 
provided. However, when there is an extensive evidence base regarding what works for parents and children, it makes little sense for funding to be directed to evidenceinformed parenting supports rather than to evidence-based parenting programs.

To date, funding for EBPSs has often been piecemeal. It is almost impossible to find out how much is spent by governments each year on the delivery of EBPSs. With no clearly defined line items in government budgets, it is impossible to know whether funding for EBPSs is improving, stable, or decreasing. Policy makers therefore need to ensure that they are directing funding to EBPSs in a transparent way that promotes accountability. We argue that to achieve wider take-up of EBPSs, a multi-level, progressive approach based on a public health or population-based model is needed [as outlined in 31,106$]$. In order to influence the bulk of the population of families, the greatest investment should be in universal primary prevention activities located within service settings that are widely available [31]. Traditionally, EBPSs have mainly been delivered through referral to mental health, specialised education, and mandated social welfare contexts, and delivered in person. Yet there are other untapped and understudied opportunities to positively influence the parent-child relationship. To influence the bulk of the population of families, policy makers need to ensure that they are funding multiple non-stigmatising "soft-entry" points for parents. "Soft-entry" points could include (a) universal services, like education and primary health care; (b) organisations that families are already in contact with, such as early childhood settings, schools, community sporting organisations, religious organisations, music and artistic activities, and general practice medical services; as well as (c) social welfare and dedicated referral services [106].

An additional barrier to improving the reach of EBPSs is an assumption that there is a one-size-fits-all approach to parenting support. There are a range of EBPSs 
based on different theoretical orientations, use a variety of delivery modalities, and cater for differing parents' needs, values, and preferred parenting practices. The evidence shown in Table 1 indicates that EBPSs can effectively be tailored at the culture-level and many other broad participant-level groupings. There are also EBPSs, such as the Family Check-Up, which tailor the intervention at the family-level [107, 108]. Parents should be provided with some level of choice so that they can find an EBPS that fits their approach to parenting as well as the EBPS that meets their cultural/religious/family-level needs; this is, provided equally strong evidence for equally strong program effects. However, access to a range of EBPSs remains limited in HICs and LMICs. Inclusivity is also needed, such that all relevant caregivers are able to participate in EBPSs appropriate to their needs $[109,110]$. This includes parents from the LGBTIQ+ community; fathers [111]; parents of children with developmental disabilities; parents in rural and remote settings; and parents from ethnically and culturally diverse groups, including Indigenous parents.

\section{Funding Research on EBPSs.}

Given the crucial importance of parenting and EBPSs, we believe it is alarming that only a small proportion of research funds focus on the continued advancement of evidence for EBPSs and the implementation of EBPSs, with some areas barely attracting government funding. We do not raise this point to feather our nests, but rather to highlight that for population reach to be realised, further consideration is needed regarding for whom, in what context, and in what combination, different EBPSs work. None of the currently available programs are a panacea and there are non-responders to every intervention. Further research is needed to identify how to further attract parents to engage in EBPSs, the variables that influence response to intervention, and the mechanisms of change underlying specific 
interventions, in order to inspire innovation in the development and translation of EBPSs. Focussed research is also needed on the implementation of EBPSs in ways that are efficient, cost-effective or cost-neutral, and how to get systems to adopt the use of EBPSs [112].

Research can only be conducted if there is funding to support it. In a recent review of Australian federal government competitive research grant schemes from 2010-2020, it was found that less than $1 \%$ of funding awarded by the Australian Research Council and the National Health and Medical Research Council was for parenting intervention research [113]. Of those studies awarded funding, each targeted between one and four of the outcome domains outlined in Table 1 [113]. Some outcomes attracted more funding (i.e. those with outcomes of child physical health, and child mental health) whereas others attracted substantially less (i.e. those with outcomes of prevention of child maltreatment, and improving child and adolescent academic achievement).

The reasons EBPSs attract such a small proportion of the research and service delivery funding budgets remain unclear. It may be due to a misunderstanding by policy makers and reviewers of the broad range of impacts that EBPSs touch, or viewing EBPSs as governance of 'private family life' [38]. Alternatively, it may be because within the wider population, parents are not viewed as important "change agents" for enhancing the wellbeing of children, preventing the development of difficulties, and reducing clinically diagnosed disorders. In LMICs, policy makers may have concerns that parenting interventions are very costly, or they do not believe that they work in settings with high violence rates [89]. Concerns about effectiveness in LMICs may be at odds with the evidence (for example, EBPSs can be effective in reducing violence and neglect of adolescents in LMICs [89]), yet such beliefs may 
still remain a barrier to implementation in LMICs. It may also be unclear to policy makers where the onus of responsibility lies for delivery of EBPSs, that is, whether they should they be delivered via health, education, child protection, criminal justice or other government portfolios. This lack of clarity means parenting research sits outside any direct source of research funding. A silo-based approach to funding of research appears to make little sense when many EBPSs impact diverse outcomes that cut across several different government portfolios and policy agendas.

\section{Ensuring Workforce Readiness.}

A further challenge in extending reach of EBPSs is ensuring that there is a workforce able to readily implement these programs. Most helping professionals receive little training in EBPSs in their discipline-specific professional education. Psychologists, social workers, nurses, general practitioners, paediatricians, educators and counsellors would all benefit from better pre-service training, specifically systematic skills-based training in a least one EBPS model. The impact of COVID-19, requiring a pivot to online training, may provide additional avenues for training of parent support practitioners. Professional associations that develop guidelines for university-based training should therefore consider adding guidelines to ensure the inclusion of systematic skills-based training in at least one EBPS model.

To close the access gap, it may also be necessary to expand the interprofessional, non-professional, and potentially lay workforce for EBPSs [105]. For example, there is evidence that EBPSs can be provided effectively by early childhood educators [114], and trained interprofessional volunteers (e.g., those with a relevant background within the pedagogical, teaching, social, or health profession [115]). Such solutions to providing EBPSs are particularly needed in LMICs where there may not be a readily available professional workforce who can provide EBPSs. 
Regardless of setting, it is important to ensure training of the workforce to ensure program fidelity.

Improving the Reach and Impact of EBPSs: Two Examples of Supportive Policies.

There are several times where research outcomes have been used to guide policy decisions to increase the reach of EBPSs. For example, in 2015 the Queensland Government funded the state-wide implementation of the full 5-level Triple P system, free of charge for all parents of children from birth to age 16 [116]. This policy-based investment came about because the government was convinced by the strength of available evidence that the programs comprising each level would benefit children and families. Approximately 400,000 parents have reported participating in the program.

The Communities That Care [CTC; 117] approach is another example of how policies can be used to support the selection and use of EBPSs to address populationwide problems. In the CTC approach training is provided to local government coalitions to complete epidemiologically valid surveys with children and young people. These survey results are then used to prioritise family risk and protective factors to be measurably enhanced through EBPSs. The CTC process has assisted coalitions of local government areas to increase their investment in evidence-based family and community programs [117], with flow-on benefits such as reducing child hospital injury admissions across large municipalities [118]. Thus, we believe that it is possible and prudent for policymakers to use research outcomes to guide policy decisions to increase the reach of EBPSs, and subsequently improve the wellbeing of families concurrently and in the future. 


\section{Summary}

The majority of mental health problems have their origins in childhood and adolescence, and it is well documented that investing in the mental health of future generations has long-term benefits for all aspects of society [42, 43]. EBPSs can successfully create conditions for change for parents and children across a range of outcomes, including child and adolescent mental health, physical health, competencies, and academic outcomes; parental skills, competencies, wellbeing and mental health; and prevention of child maltreatment and family violence. Thus, EBPSs provide an effective means to address several high priority mental health, physical health, and social problems. Yet few policies adequately support the use of EBPSs as mechanisms to support parents and children, and address these high priority problems. We have identified that policy makers need to (a) ensure that they are funding multiple non-stigmatising "soft-entry" points into a variety of EBPSs for parents/caregivers at the population-level; (b) address funding barriers so that parents/caregivers are able to access EBPSs; (c) ensure that funding for EBPSs is transparent and promotes accountability; (d) fund research examining for whom, in what context, and in what combination, different EBPSs work. Further, to ensure workforce readiness, professional associations that develop guidelines for universitybased training should add guidelines to ensure the inclusion of systematic skills-based training in at least one EBPS model. It is vital that research efforts and policies continue to create more favourable community conditions that support competent parenting, so that the reach of EBPSs can become population-wide and socially normative. 


\section{References}

[1] Collins, W. A., Maccoby, E. E., Steinberg, L., Hetherington, E. M., \& Bornstein, M. H. (2000). Contemporary research on parenting: The case for nature and nurture. American Psychologist, 55(2), 218-232. https://doi.org/10.1037/0003066X.55.2.218

[2] Kim-Cohen, J., Caspi, A., Moffitt, T. E., Harrington, H., Milne, B. J., \& Poulton, R. (2003). Prior juvenile diagnoses in adults with mental disorder: developmental follow-back of a prospective-longitudinal cohort. Archives of General Psychiatry, 60(7), 709-717. https://doi.org/10.1001/archpsyc.60.7.709

[3] Odgers, C. L., Caspi, A., Broadbent, J. M., et al. (2007). Prediction of differential adult health burden by conduct problem subtypes in males. Archives of General Psychiatry, 64(4), 476-484. https://doi.org/10.1001/archpsyc.64.4.476

[4] Copeland, W., Shanahan, L., Costello, E., \& Angold, A. (2009). Childhood and adolescent psychiatric disorders as predictors of young adult disorders. Archives of General Psychiatry, 66(7), 764-772. https://doi.org/10.1001/archgenpsychiatry.2009.85

[5] Toumbourou, J. W., Rowland, B., Ghayour-Minaie, M., Sherker, S., Patton, G. C., \& Williams, J. (2018). Student survey trends in reported alcohol use and influencing factors in Australia. Drug and Alcohol Review, 37(S1), S58-S66. https://doi.org/10.1111/dar.12645

[6] Felitti, V. J., Anda, R. F., Nordenberg, D., et al. (1998). Relationship of childhood abuse and household dysfunction to many of the leading causes of death in adults: The Adverse Childhood Experiences (ACE) Study. American journal of preventive medicine, 14(4), 245-258. https://doi.org/10.1016/S0749$\underline{3797(98) 00017-8}$ 
[7] Gershoff, E. T., \& Grogan-Kaylor, A. (2016). Spanking and child outcomes: Old controversies and new meta-analyses. Journal of Family Psychology, 30(4), 453-469. https://doi.org/10.1037/fam0000191

[8] Prinz, R. J. (2016). Parenting and family support within a broad child abuse prevention strategy: Child maltreatment prevention can benefit from public health strategies. Child Abuse \& Neglect, 51, 400-406. https://doi.org/10.1016/j.chiabu.2015.10.015

[9] Leijten, P., Gardner, F., Landau, S., et al. (2018). Research Review: Harnessing the power of individual participant data in a meta-analysis of the benefits and harms of the Incredible Years parenting program. Journal of Child Psychology and Psychiatry, 59(2), 99-109. https://doi.org/10.1111/jcpp.12781

[10] Mingebach, T., Kamp-Becker, I., Christiansen, H., \& Weber, L. (2018). Metameta-analysis on the effectiveness of parent-based interventions for the treatment of child externalizing behavior problems. PloS one, 13(9). https://doi.org/10.1371/journal.pone.0202855

[11] Piquero, A. R., Jennings, W. G., Diamond, B., et al. (2016). A meta-analysis update on the effects of early family/parent training programs on antisocial behavior and delinquency. Journal of Experimental Criminology, 12(2), 229248. https://doi.org/10.1007/s11292-016-9256-0

[12] van Aar, J., Leijten, P., de Castro, B. O., \& Overbeek, G. (2017). Sustained, fadeout or sleeper effects? A systematic review and meta-analysis of parenting interventions for disruptive child behavior. Clinical Psychology Review, 51, 153-163. https://doi.org/10.1016/j.cpr.2016.11.006

[13] Michelson, D., Davenport, C., Dretzke, J., Barlow, J., \& Day, C. (2013). Do evidence-based interventions work when tested in the "real world?" A 
systematic review and meta-analysis of parent management training for the treatment of child disruptive behavior. Clinical Child and Family Psychology Review, 16(1), 18-34. https://doi.org/10.1007/s10567-013-0128-0

[14] Ruane, A., \& Carr, A. (2019). Systematic Review and Meta-analysis of Stepping Stones Triple P for Parents of Children with Disabilities. Family Process, 58(1), 232-246. https://doi.org/10.1111/famp.12352

[15] Spencer, C. M., Topham, G. L., \& King, E. L. (2020). Do online parenting programs create change?: A meta-analysis. Journal of Family Psychology, 34(3), 364-374. https://doi.org/10.1037/fam0000605

[16] Gardner, F., Montgomery, P., \& Knerr, W. (2016). Transporting evidence-based parenting programs for child problem behavior (age 3-10) between countries: Systematic review and meta-analysis. Journal of Clinical Child \& Adolescent Psychology, 45(6), 749-762. https://doi.org/10.1080/15374416.2015.1015134

[17] Sanders, M. R., Kirby, J. N., Tellegen, C. L., \& Day, J. J. (2014). The Triple PPositive Parenting Program: A systematic review and meta-analysis of a multi-level system of parenting support. Clinical Psychology Review, 34(4), 337-357. https://doi.org/10.1016/j.cpr.2014.04.003

[18] Armstrong, E., Eggins, E., Reid, N., Harnett, P., \& Dawe, S. (2018). Parenting interventions for incarcerated parents to improve parenting knowledge and skills, parent well-being, and quality of the parent-child relationship: A systematic review and meta-analysis. Journal of Experimental Criminology, 14(3), 279-317. https://doi.org/10.1007/s11292-017-9290-6

[19] Shah, R., Kennedy, S., Clark, M. D., Bauer, S. C., \& Schwartz, A. (2016). Primary Care-Based Interventions to Promote Positive Parenting Behaviors: 
A Meta-analysis. Pediatrics, 137(5), e20153393.

https://doi.org/10.1542/peds.2015-3393

[20] Solomon, D. T., Niec, L. N., \& Schoonover, C. E. (2017). The Impact of Foster Parent Training on Parenting Skills and Child Disruptive Behavior: A MetaAnalysis. Child Maltreatment, 22(1), 3-13. https://doi.org/10.1177/1077559516679514

[21] Furlong, M., McGilloway, S., Bywater, T., Hutchings, J., Smith, S. M., \& Donnelly, M. (2012). Behavioural and cognitive-behavioural group-based parenting programmes for early -onset conduct problems in children aged 3 to 12 years. Campbell Systematic Reviews, 8(1), 1-239. https://doi.org/10.1002/14651858.CD008225.pub2

[22] Daley, D., Van Der Oord, S., Ferrin, M., et al. (2018). Practitioner review: current best practice in the use of parent training and other behavioural interventions in the treatment of children and adolescents with attention deficit hyperactivity disorder. Journal of Child Psychology and Psychiatry, 59(9), 932-947. https://doi.org/10.1111/jcpp.12825

[23] Gubbels, J., van der Put, C. E., \& Assink, M. (2019). The effectiveness of parent training programs for child maltreatment and their components: A metaanalysis. International journal of environmental research and public health, 16(13), 2404. https://doi.org/10.3390/ijerph16132404

[24] Lundahl, B. W., Nimer, J., \& Parsons, B. (2006). Preventing child abuse: A meta-analysis of parent training programs. Research on Social Work Practice, 16(3), 251-262. https://doi.org/10.1177/1049731505284391

[25] van der Put, C. E., Assink, M., Gubbels, J., \& van Solinge, N. F. B. (2018). Identifying effective components of child maltreatment interventions: A meta- 
analysis. Clinical Child and Family Psychology Review, 21(2), 171-202. https://doi.org/10.1007/s10567-017-0250-5

[26] Jeong, J., Franchett, E. E., Ramos de Oliveira, C. V., Rehmani, K., \& Yousafzai, A. K. (2021). Parenting interventions to promote early child development in the first three years of life: A global systematic review and meta-analysis. PLoS medicine, 18(5), e1003602. https://doi.org/10.1371/journal.pmed.1003602

[27] Clancy, E., Benstead, M., Little, K., et al. (2019). Family Partnerships to Support Children and Young People's Mental Health: an Evidence Check: Rapid review brokered by the Sax Institute (www.saxinstitute.org.au) for Be You. Melbourne, Vic., Australia: Sax Institute.

[28] Marmot, M., \& Bell, R. (2012). Fair society, healthy lives. Public health, 126, S4-S10. https://doi.org/10.1016/j.puhe.2012.05.014

[29] World Health Organization. (2018). Nurturing Care for Early Childhood Development: A Framework for Helping Children Survive and Thrive to Transform Health and Human Potential. Geneva, Switzerland: World Health Organization.

[30] Prinz, R. J., \& Sanders, M. R. (2007). Adopting a population-level approach to parenting and family support interventions. Clinical Psychology Review, 27(6), 739-749. https://doi.org/10.1016/j.cpr.2007.01.005

[31] Sanders, M., Higgins, D., \& Prinz, R. (2018). A population approach to the prevention of child maltreatment: Rationale and implications for research, policy and practice. Family Matters(100), 62-70. https://doi.org/10.3316/ielapa.765584280626723 
[32] Prinz, R. J., Sanders, M. R., Shapiro, C. J., Whitaker, D. J., \& Lutzker, J. R. (2009). Population-based prevention of child maltreatment: The US Triple P system population trial. Prevention Science, 10(1), 1-12. https://doi.org/10.1007/s11121-009-0123-3

[33] Doyle, O., Hegarty, M., \& Owens, C. (2018). Population-based system of parenting support to reduce the prevalence of child social, emotional, and behavioural problems: Difference-in-differences study. Prevention Science, 19(6), 772-781. https://doi.org/10.1007/s11121-018-0907-4

[34] Toumbourou, J. W., \& Gregg, M. E. (2002). Impact of an empowerment-based parent education program on the reduction of youth suicide risk factors. Journal of Adolescent Health, 31(3), 279-287.

[35] Toumbourou, J. W., Gregg, M. E. D., Shortt, A. L., Hutchinson, D. M., \& Slaviero, T. M. (2013). Reduction of adolescent alcohol use through familyschool intervention: A randomized trial. Journal of Adolescent Health, 53(6), 778-784. https://doi.org/10.1016/j.jadohealth.2013.07.005

[36] Sanders, M. R., Divan, G., Singhal, M., et al. (2021). Scaling up parenting interventions is critical for attaining the Sustainable Development Goals. Child Psychiatry \& Human Development https://doi.org/10.1007/s10578-021$\underline{01171-0}$

[37] Daly, M. (2015). Parenting support as policy field: An analytic framework. Social Policy and Society, 14(4), 597-608. https://doi.org/10.1017/S1474746415000317

[38] Daly, M. (2015). Introduction: Parenting Support in European Countries: A Complex Development in Social Policy. Social Policy and Society, 14(4), 593-595. https://doi.org/10.1017/S1474746415000317 
[39] McAdams, T. A., Neiderhiser, J. M., Rijsdijk, F. V., Narusyte, J., Lichtenstein, P., \& Eley, T. C. (2014). Accounting for genetic and environmental confounds in associations between parent and child characteristics: a systematic review of children-of-twins studies. Psychological bulletin, 140(4), 1138-1173. https://doi.org/10.1037/a0036416

[40] Teti, D. M., Cole, P. M., Cabrera, N., Goodman, S. H., \& McLoyd, V. C. (2017). Supporting Parents: How Six Decades of Parenting Research Can Inform Policy and Best Practice. Social Policy Report, 30(5), 1-34. https://doi.org/10.1002/j.2379-3988.2017.tb00090.x

[41] World Health Organization. (2020). WHO Guideline on parenting to prevent child maltreatment and promote positive development in children aged 0-17 years [Press release]. Retrieved from https://www.who.int/news/item/01-032020-guideline-on-parent-training-to-prevent-child-maltreatment-andpromote-the-positive-development-of-children-aged-0-17-years

[42] UNICEF Australia. (2020). "Living in Limbo": The views and experiences of young people in Australia at the start of the COVID-19 pandemic and national response (pp. 1-17). Australia: UNICEF.

[43] Green, P. (2020). Risks to children and young people during COVID-19 pandemic. Bmj(369), m1669. https://doi.org/10.1136/bmj.m1669

[44] Zubrick, S. R., Smith, G. J., Nicholson, J., Sanson, A., \& Jackiewicz, T. A. (2008). Parenting and families in Australia. FaHCSIA Social Policy Research Paper.

[45] Sanders, M. R., \& Morawska, A. (2017). Towards an evidence-based population approach to supporting parenting in the early years Transforming Infant 
Wellbeing: Research, Policy and Practice for the First 1001 Critical Days (1st ed.). London, UK: Routledge.

[46] Sanders, M. R., \& Mazzucchelli, T. G. (2018). Core principles and techniques of positive parenting. In M. R. Sanders \& T. G. Mazzucchelli (Eds.), The power of positive parenting: Transforming the lives of children, parents, and communities using the Triple P system: Oxford University Press.

[47] Sanders, M. R., \& Turner, K. M. (2018). The importance of parenting in influencing the lives of children Handbook of Parenting and Child Development Across the Lifespan (pp. 3-26): Springer. https://doi.org/10.1007/978-3-319-94598-9.

[48] Mullan, K., \& Higgins, D. (2014). A safe and supportive family environment for children: Key components and links to child outcomes (Department of Social Services, Trans.) Australian Government Department of Social Services Occasional Paper. Canberra, ACT, Australia.

[49] Alexander, K. (2018). Integrative review of the relationship between mindfulness-based parenting interventions and depression symptoms in parents. Journal of Obstetric, Gynecologic \& Neonatal Nursing, 47(2), 184190. https://doi.org/10.1016/j.jogn.2017.11.013

[50] Law, E. F., Fisher, E., Fales, J., Noel, M., \& Eccleston, C. (2014). Systematic review and meta-analysis of parent and family-based interventions for children and adolescents with chronic medical conditions. Journal of Pediatric Psychology, 39(8), 866-886. https://doi.org/10.1093/jpepsy/jsu032

[51] Townshend, K., Jordan, Z., Stephenson, M., \& Tsey, K. (2016). The effectiveness of mindful parenting programs in promoting parents' and children's wellbeing: a systematic review. JBI Database of Systematic 
Reviews and Implementation Reports, 14(3), 139-180.

https://doi.org/10.11124/JBISRIR-2016-2314

[52] Shaw, D. S., Connell, A., Dishion, T. J., Wilson, M. N., \& Gardner, F. (2009). Improvements in maternal depression as a mediator of intervention effects on early childhood problem behavior. Development and Psychopathology, 21(2), 417-439. https://doi.org/10.1017/S0954579409000236

[53] Macvean, M., Shlonsky, A., Mildon, R., \& Devine, B. (2017). Parenting interventions for indigenous child psychosocial functioning: A scoping review. Research on Social Work Practice, 27(3), 307-334. https://doi.org/10.1177/1049731514565668

[54] McCoy, A., Melendez-Torres, G., \& Gardner, F. (2020). Parenting interventions to prevent violence against children in low-and middle-income countries in East and Southeast Asia: a systematic review and multi-level meta-analysis. Child Abuse \& Neglect, 103, 104444. https://doi.org/10.1016/j.chiabu.2020.104444

[55] Richardson, D., Dugarova, E., Higgins, D., et al. (2020). Families, Family Policy and the Sustainable Development Goals. Innocenti, Florence.

[56] Ramsey, A. T., Proctor, E. K., Chambers, D. A., et al. (2019). Designing for Accelerated Translation (DART) of emerging innovations in health. Journal of clinical and translational science, 3(2-3), 53-58. https://doi.org/10.1017/cts.2019.386

[57] Wittkowski, A., Dowling, H., \& Smith, D. M. (2016). Does Engaging in a Group-Based Intervention Increase Parental Self-efficacy in Parents of Preschool Children? A Systematic Review of the Current Literature. Journal 
of Child and Family Studies, 25(11), 3173-3191.

https://doi.org/10.1007/s10826-016-0464-Z

[58] Hohlfeld, A. S. J., Harty, M., \& Engel, M. E. (2018). Parents of children with disabilities: A systematic review of parenting interventions and self-efficacy. African Journal of Disability, 7, 1-12. https://doi.org/10.4102/ajod.v7i0.437

[59] Barlow, J., \& Coren, E. (2018). The Effectiveness of Parenting Programs:A Review of Campbell Reviews. Research on Social Work Practice, 28(1), 99102. https://doi.org/10.1177/1049731517725184

[60] Tremblay, M. D., \& Sutherland, J. E. (2017). The Effectiveness of Parenting Programs for Incarcerated Mothers: A Systematic Review. Journal of Child and Family Studies, 26(12), 3247-3265. https://doi.org/10.1007/s10826-017$\underline{0900-8}$

[61] Marcus, R., Kruja, K., \& Rivett, J. (2019). What are the impacts of parenting programmes on adolescents? A review of evidence from low-and middleincome countries Gender \& Adolescence: Global Evidence.

[62] Medlow, S., Klineberg, E., Jarrett, C., \& Steinbeck, K. (2016). A systematic review of community-based parenting interventions for adolescents with challenging behaviours. Journal of adolescence, 52, 60-71.

https://doi.org/10.1016/j.adolescence.2016.07.003

[63] Tellegen, C. L., \& Sanders, M. R. (2013). Stepping Stones Triple P-Positive Parenting Program for children with disability: A systematic review and metaanalysis. Research in Developmental Disabilities, 34(5), 1556-1571. https://doi.org/10.1016/j.ridd.2013.01.022

[64] Barlow, J., Bergman, H., Kornør, H., Wei, Y., \& Bennett, C. (2016). Group based parent training programmes for improving emotional and behavioural 
adjustment in young children. Cochrane Database of Systematic Reviews(8). https://doi.org/10.1002/14651858.CD003680.pub3

[65] Thongseiratch, T., Leijten, P., \& Melendez-Torres, G. (2020). Online parent programs for children's behavioral problems: a meta-analytic review. European Child \& Adolescent Psychiatry, 29, 1555-1568. https://doi.org/10.1007/s00787-020-01472-0

[66] Yap, M. B., Morgan, A. J., Cairns, K., Jorm, A. F., Hetrick, S. E., \& Merry, S. (2016). Parents in prevention: a meta-analysis of randomized controlled trials of parenting interventions to prevent internalizing problems in children from birth to age 18. Clinical Psychology Review, 50, 138-158. https://doi.org/10.1016/j.cpr.2016.10.003

[67] Lee, P.-c., Niew, W.-i., Yang, H.-j., Chen, V. C.-h., \& Lin, K.-c. (2012). A metaanalysis of behavioral parent training for children with attention deficit hyperactivity disorder. Research in Developmental Disabilities, 33(6), 20402049. https://doi.org/10.1016/j.ridd.2012.05.011

[68] Oono, I. P., Honey, E. J., \& McConachie, H. (2013). Parent-mediated early intervention for young children with autism spectrum disorders (ASD). Evidence-Based Child Health: A Cochrane Review Journal, 8(6), 2380-2479. https://doi.org/10.1002/ebch.1952

[69] Roberts, M. Y., \& Kaiser, A. P. (2011). The effectiveness of parent-implemented language interventions: A meta-analysis. American Journal of SpeechLanguage Pathology, 20(3), 180-199. https://doi.org/10.1044/1058$\underline{0360(2011 / 10-0055)}$

[70] Coren, E., Thomae, M., \& Hutchfield, J. (2011). Parenting training for intellectually disabled parents: A Cochrane systematic review. Research on 
Social Work Practice, 21(4), 432-441.

https://doi.org/10.1177/1049731511399586

[71] Einfeld, S., Sanders, M. R., Tonge, B., Gray, K., Sofronoff, K., \& Team, T. M. (2018). Is statewide delivery of Stepping Stones Triple P effective? Sydney, Australia: The University of Sydney.

[72] Brennan, L. M., Shelleby, E. C., Shaw, D. S., Gardner, F., Dishion, T. J., \& Wilson, M. (2013). Indirect effects of the family check-up on school-age academic achievement through improvements in parenting in early childhood. Journal of Educational Psychology, 105(3), 762-773. https://doi.org/10.1037/a0032096

[73] Lahti, M., Evans, C. B., Goodman, G., Schmidt, M. C., \& LeCroy, C. W. (2019). Parents as Teachers (PAT) home-visiting intervention: A path to improved academic outcomes, school behavior, and parenting skills. Children and Youth Services Review, 99, 451-460. https://doi.org/10.1016/j.childyouth.2019.01.022

[74] Sartore, G.-M., Macvean, M., Devine, B., \& Pourliakas, A. (2016). Interventions for parents and families: the evidence for improving emotional outcomes for children. Prepared for The Benevolent Society by the Parenting Research Centre, Victoria, Australia.

[75] England-Mason, G., \& Gonzalez, A. (2020). Intervening to shape children's emotion regulation: A review of emotion socialization parenting programs for young children. Emotion, 20(1), 98-104. https://doi.org/10.1037/emo0000638

[76] Dyches, T. T., Smith, T. B., Korth, B. B., \& Mandleco, B. (2018). Effects of Parent-Implemented Interventions on Outcomes for Children with 
Developmental Disabilities: A Meta-Analysis. Perspectives on Early

Childhood Psychology and Education, 3(1), 137-168.

[77] Morawska, A., Mitchell, A., \& Mihelic, M. (2020). A systematic review of parenting interventions for child chronic health conditions. Journal of Child Health Care, 24(4), 603-628. https://doi.org/10.1177/1367493519882850

[78] Hubbs-Tait, L., Kimble, A., Hingle, M., Novotny, R., \& Fiese, B. (2016). Systematic review of child obesity prevention and treatment trials addressing parenting. The FASEB Journal, 30(1), 1155.1156-1155.1156. https://doi.org/10.1096/fasebj.30.1_supplement.1155.6

[79] Loveman, E., Al Khudairy, L., Johnson, R. E., et al. (2015). Parent -only interventions for childhood overweight or obesity in children aged 5 to 11 years. Cochrane Database of Systematic Reviews(12). https://doi.org/10.1002/14651858.CD012008

[80] Redsell, S. A., Edmonds, B., Swift, J. A., et al. (2016). Systematic review of randomised controlled trials of interventions that aim to reduce the risk, either directly or indirectly, of overweight and obesity in infancy and early childhood. Maternal \& Child Nutrition, 12(1), 24-38. https://doi.org/10.1111/mcn.12184

[81] Kader, M., Sundblom, E., \& Elinder, L. S. (2015). Effectiveness of universal parental support interventions addressing children's dietary habits, physical activity and bodyweight: A systematic review. Preventive Medicine, 77, 5267. https://doi.org/10.1016/j.ypmed.2015.05.005

[82] Hammersley, M. L., Jones, R. A., \& Okely, A. D. (2016). Parent-focused childhood and adolescent overweight and obesity ehealth interventions: A 
systematic review and meta-analysis. Journal of Medical Internet Research, 18(7), e203. https://doi.org/10.2196/jmir.5893

[83] Schlechter, C. R., Rosenkranz, R. R., Guagliano, J. M., \& Dzewaltowski, D. A. (2016). A systematic review of children's dietary interventions with parents as change agents: Application of the RE-AIM framework. Preventive Medicine, 91, 233-243. https://doi.org/10.1016/j.ypmed.2016.08.030

[84] Mihelic, M., Morawska, A., \& Filus, A. (2017). Effects of early parenting interventions on parents and infants: A meta-analytic review. Journal of Child and Family Studies 26, 1507-1526. https://doi.org/10.1007/s10826-017-0675y

[85] Foxcroft, D. R., \& Tsertsvadze, A. (2011). Universal family-based prevention programs for alcohol misuse in young people Cochrane Database of Systematic Reviews (pp. CD009308).

[86] Thomas, R. E., Baker, P. R., Thomas, B. C., \& Lorenzetti, D. L. (2015). Family based programmes for preventing smoking by children and adolescents. Cochrane Database of Systematic Reviews(2). https://doi.org/10.1002/14651858.CD004493.pub3.

[87] Allen, M. L., Garcia-Huidobro, D., Porta, C., et al. (2016). Effective parenting interventions to reduce youth substance use: a systematic review. Pediatrics, 138(2). https://doi.org/10.1542/peds.2015-4425

[88] Kuntsche, S., \& Kuntsche, E. (2016). Parent-based interventions for preventing or reducing adolescent substance use-A systematic literature review. Clinical Psychology Review, 45, 89-101. https://doi.org/10.1016/j.cpr.2016.02.004

[89] Marcus, R., Rivett, J., \& Kruja, K. (2021). How far do parenting programmes help change norms underpinning violence against adolescents? Evidence from 
low and middle-income countries. Global Public Health, 16(6), 820-841. https://doi.org/10.1080/17441692.2020.1776364

[90] Buckle, L., Simpson, B., Berger, S., \& Metcalfe, M. (2014). Prevention and Early Intervention for Domestic Violence.

[91] Bacchus, L. J., Colombini, M., Contreras Urbina, M., et al. (2017). Exploring opportunities for coordinated responses to intimate partner violence and child maltreatment in low and middle income countries: a scoping review. Psychology, health \& medicine, 22(sup1), 135-165. https://doi.org/10.1080/13548506.2016.1274410

[92] Kaspiew, R., Horsfall, B., Qu, L., et al. (2017). Domestic and family violence and parenting: Mixed method insights into impact and support needs: Final report. Sydney, Australia: ANROWS Horizons.

[93] Johnson, S. E., Lawrence, D., Sawyer, M., \& Zubrick, S. R. (2017). Mental disorders in Australian 4- to 17- year olds: Parent-reported need for help. Australian \& New Zealand Journal of Psychiatry, 52(2), 149-162. https://doi.org/10.1177/0004867417706032

[94] Merikangas, K. R., He, J.-p., Burstein, M., et al. (2011). Service utilization for lifetime mental disorders in US adolescents: results of the National Comorbidity Survey-Adolescent Supplement (NCS-A). Journal of the American Academy of Child \& Adolescent Psychiatry, 50(1), 32-45. https://doi.org/10.1016/j.jaac.2010.10.006

[95] McCoy, A., Lachman, J. M., Ward, C. L., et al. (2021). Feasibility pilot of an adapted parenting program embedded within the Thai public health system. BMC Public Health, 21(1), 1-19. https://doi.org/10.1186/s12889-021-11081-4 
[96] Allen, M. L., Garcia-Huidobro, D., Porta, C., et al. (2016). Effective parenting interventions to reduce youth substance use: a systematic review. Pediatrics, 138(2), e20154425. https://doi.org/10.1542/peds.2015-4425

[97] Dadds, M. R., Thai, C., Mendoza Diaz, A., et al. (2019). Therapist-assisted online treatment for child conduct problems in rural and urban families: Two randomized controlled trials. Journal of Consulting and Clinical Psychology, 87(8), 706-719. https://doi.org/10.1037/ccp0000419

[98] Tse, Y. J., McCarty, C. A., Stoep, A. V., \& Myers, K. M. (2015). Teletherapy delivery of caregiver behavior training for children with attention-deficit hyperactivity disorder. Telemedicine journal and e-health : the official journal of the American Telemedicine Association, 21(6), 451-458. https://doi.org/10.1089/tmj.2014.0132

[99] Baumel, A., Pawar, A., Kane, J. M., \& Correll, C. U. (2016). Digital Parent Training for Children with Disruptive Behaviors: Systematic Review and Meta-Analysis of Randomized Trials. Journal of Child and Adolescent Psychopharmacology, 26(8), 740-749. https://doi.org/10.1089/cap.2016.0048

[100] Breitenstein, S. M., Gross, D., \& Christophersen, R. (2014). Digital Delivery Methods of Parenting Training Interventions: A Systematic Review. Worldviews on Evidence-Based Nursing, 11(3), 168-176. https://doi.org/10.1111/wvn.12040

[101] Connell, S., Sanders, M. R., \& Markie-Dadds, C. (1997). Self-Directed Behavioral Family Intervention for Parents of Oppositional Children in Rural and Remote Areas. Behavior Modification, 21(4), 379-408.

https://doi.org/10.1177/01454455970214001 
[102] Markie-Dadds, C., \& Sanders, M. R. (2006). A Controlled Evaluation of an Enhanced Self-Directed Behavioural Family Intervention for Parents of Children With Conduct Problems in Rural and Remote Areas. Behaviour Change, 23(1), 55-72. https://doi.org/10.1375/bech.23.1.55

[103] Comer, J. S., Furr, J. M., Miguel, E. M., et al. (2017). Remotely delivering realtime parent training to the home: An initial randomized trial of Internetdelivered parent-child interaction therapy (I-PCIT). Journal of Consulting and Clinical Psychology, 85(9), 909-917. https://doi.org/10.1037/ccp0000230

[104] Day, J. J., \& Sanders, M. R. (2018). Do Parents Benefit From Help When Completing a Self-Guided Parenting Program Online? A Randomized Controlled Trial Comparing Triple P Online With and Without Telephone Support. Behavior Therapy, 49(6), 1020-1038. https://doi.org/10.1016/j.beth.2018.03.002

[105] Weisenmuller, C., \& Hilton, D. (2021). Barriers to access, implementation, and utilization of parenting interventions: Considerations for research and clinical applications. American Psychologist, 76(1), 104-115. https://doi.org/10.1037/amp0000613

[106] Higgins, D., Sanders, M. R., Lonne, B., \& Richardson, D. (2019). Families private and sacred: How to raise the curtain and implement family support from a public health perspective. In B. Lonne, D. Scott, D. Higgins \& T. Herrenkohl (Eds.), Re-visioning public health approaches for protecting children (pp. 127-143): Springer.

[107] Pelham, W. E., Dishion, T. J., Tein, J.-Y., Shaw, D. S., \& Wilson, M. N. (2017). What doesn't work for whom? Exploring heterogeneity in responsiveness to the family check-up in early childhood using a mixture 
model approach. Prevention Science, 18(8), 911-922.

https://doi.org/10.1007/s11121-017-0805-1

[108] Shaw, D. S., Sitnick, S. L., Brennan, L. M., et al. (2016). The long-term effectiveness of the Family Check-Up on school-age conduct problems: Moderation by neighborhood deprivation. Development and Psychopathology, 28(4pt2), 1471-1486. https://doi.org/10.1017/S0954579415001212

[109] Gonzalez, C., Morawska, A., \& Haslam, D. (2018). Enhancing initial parental engagement in interventions for parents of young children: A systematic review of experimental studies. Clinical Child and Family Psychology Review, 21(3), 415-432. https://doi.org/10.1007/s10567-018-0259-4

[110] Dadds, M. R., Thai, C., Mendoza Diaz, A., et al. (2019). Therapist-assisted online treatment for child conduct problems in rural and urban families: Two randomized controlled trials. Journal of Consulting and Clinical Psychology, 87(8), 706.

[111] Lechowicz, M. E., Jiang, Y., Tully, L. A., et al. (2018). Enhancing Father Engagement in Parenting Programs: Translating Research into Practice Recommendations. Australian Psychologist, 54(2), 83-89. https://doi.org/10.1111/ap.12361

[112] Smith, J. D., Cruden, G. H., Rojas, L. M., et al. (2020). Parenting interventions in pediatric primary care: a systematic review. Pediatrics, 146(1), e20193548. https://doi.org/10.1542/peds.2019-3548

[113] Havighurst, S., Chainey, C., Doyle, F. L., et al. (under review). A Review of Australian Government Funding of Parenting Intervention Research.

[114] Tiano, J. D., \& McNeil, C. B. (2006). Training Head Start teachers in behavior management using Parent-Child Interaction Therapy: A preliminary 
investigation. Journal of Early and Intensive Behavior Intervention, 3(2), 220233. https://doi.org/10.1037/h0100334

[115] Chacko, A., \& Scavenius, C. (2018). Bending the curve: A community-based behavioral parent training model to address ADHD-related concerns in the voluntary sector in Denmark. Journal of Abnormal Child Psychology, 46(3), 505-517. https://doi.org/10.1007/s10802-017-0310-9

[116] Sofronoff, K., Gray, K. M., Einfeld, S. L., \& Tonge, B. J. (2018). Supporting families of children with a disability. In M. R. Sanders \& T. G. Mazzucchelli (Eds.), The power of positive parenting: Transforming the lives of children, parents, and communities using the Triple P system (pp. 442-454): Oxford University Press.

[117] Toumbourou, J. W., Rowland, B., Williams, J., Smith, R., \& Patton, G. C. (2019). Community intervention to prevent adolescent health behavior problems: Evaluation of communities that care in Australia. Health Psychology, 38(6), 536-544. https://doi.org/10.1037/hea0000735

[118] Berecki-Gisolf, J., Rowland, B., Reavley, N., Minuzzo, B., \& Toumbourou, J. (2020). Evaluation of community coalition training effects on youth hospitaladmitted injury incidence in Victoria, Australia: 2001-2017. Injury Prevention, 26, 463-470. https://doi.org/10.1136/injuryprev-2019-043386 


\section{Acknowledgements}

The authors would like to thank Maria Battaglia for her assistance in creating Figures 2 and 3 in this manuscript. The authors thank and acknowledge James Kirby and Kylie Burke for their input to the initial planning stages of this paper; and Mark R. Dadds, Karen Turner, and Jan M. Nicholson for their feedback on a draft of this paper. We also thank the Australian Research Council's Centre of Excellence for Children and Families over the Life Course (LCC) who provided funding to support this work and the establishment of the Parenting and Family Research Alliance (PAFRA).

\section{Conflict of Interest Statements}

M.S. is the founder and an author on various Triple P Positive Parenting Programs and a consultant to Triple P International. The Parenting and Family Support Centre is partly funded by royalties stemming from published resources of the Triple $\mathrm{P}$ - Positive Parenting Program, which is developed and owned by The University of Queensland (UQ). Royalties are also distributed to the Faculty of Health and Behavioural Sciences at UQ and contributory authors of published Triple P resources. Triple P International (TPI) Pty Ltd is a private company licensed by UniQuest Pty Ltd on behalf of UQ, to publish and disseminate Triple P worldwide. The authors of this manuscript have no share or ownership of TPI. TPI had no involvement in the study design, collection, analysis or interpretation of data, or writing of this manuscript. A.M. and M.S. receive royalties from TPI, and M.S. receives consultancy fees from TPI. V.C. and T.G.M have, or may in the future, receive royalties and/or consultancy fees from TPI. A.M., M.S., C.C., C.M. and V.C. are employees at UQ. T.G.M. holds an honorary position at UQ. 
S.H. is a co-author of the Tuning in to Kids parenting program. Proceeds from dissemination of the program provide funding for development and research of the program. Program authors and the University of Melbourne are distributed royalties from proceeds of manual sales.

J.T. holds responsibility for intellectual property management in the Resilient Families program and is a Director of Communities That Care Ltd, which holds the Australian rights to the Communities That Care process.

P.H. is the co-developer of the Parents under Pressure (PuP) program. The PuP program is owned and disseminated by Griffith University with a non-exclusive license granted to the University of Queensland. Proceeds from PuP dissemination are distributed in accordance with Griffith University policy with five per cent of training fees paid to the University of Queensland. Surplus funds from PuP training contracts are used to support research activities associated with the PuP program.

F.D., and D.H. have no conflicts of interest to report. 